\title{
Review Article \\ Recent Progress of Fabrication of Cell Scaffold by Electrospinning Technique for Articular Cartilage Tissue Engineering
}

\author{
Yingge Zhou, ${ }^{1}$ Joanna Chyu, ${ }^{2}$ and Mimi Zumwalt $\mathbb{D}^{2}$ \\ ${ }^{1}$ Department of Industrial, Manufacturing, and System Engineering, Texas Tech University, Lubbock, TX, USA \\ ${ }^{2}$ Department of Orthopedic Surgery and Rehabilitation, Texas Tech University Health Sciences Center, Lubbock, TX, USA \\ Correspondence should be addressed to Mimi Zumwalt; mimi.zumwalt@ttuhsc.edu
}

Received 23 December 2017; Revised 5 February 2018; Accepted 19 February 2018; Published 25 March 2018

Academic Editor: Feng-Huei Lin

Copyright (c) 2018 Yingge Zhou et al. This is an open access article distributed under the Creative Commons Attribution License, which permits unrestricted use, distribution, and reproduction in any medium, provided the original work is properly cited.

As a versatile nanofiber manufacturing technique, electrospinning has been widely employed for the fabrication of tissue engineering scaffolds. Since the structure of natural extracellular matrices varies substantially in different tissues, there has been growing awareness of the fact that the hierarchical 3D structure of scaffolds may affect intercellular interactions, material transportation, fluid flow, environmental stimulation, and so forth. Physical blending of the synthetic and natural polymers to form composite materials better mimics the composition and mechanical properties of natural tissues. Scaffolds with element gradient, such as growth factor gradient, have demonstrated good potentials to promote heterogeneous cell growth and differentiation. Compared to 2D scaffolds with limited thicknesses, 3D scaffolds have superior cell differentiation and development rate. The objective of this review paper is to review and discuss the recent trends of electrospinning strategies for cartilage tissue engineering, particularly the biomimetic, gradient, and 3D scaffolds, along with future prospects of potential clinical applications.

\section{Introduction}

Tissue engineering has emerged as an alternative cell-based approach designed to substitute damaged organs with tissues generated in vitro. It overcomes the barriers of conventional allograft transplantation, such as the scarcity of donor organs, the complexity of surgery, and complicated postoperative care [1]. In many cases, it involves the utilization of a scaffold, an engineered porous supporting material for tissue regeneration. Scaffolds mimic the extracellular matrix (ECM) of the original tissues and reproduce or replicate the natural tissue environment. In addition, scaffolds can foster certain mechanical and biological properties to modify the behavior of different cell phases [2-4].

Articular cartilage is tissue located between bones, which can withstand compressive and shear forces several times that of human body weight for years due to its low friction and high load bearing capacity $[5,6]$, attributed to the unique composition of its ECM [7]. However, it is also the unique ECM that makes the repair of articular cartilage extremely difficult [8]. The micro fissures caused by repetitive cyclic loading might not be visible to the eye but continuously undermine the integrity of collagen fibrils and proteoglycan network [9], causing cartilage destruction over time and leading to degenerative joint disease or osteoarthritis. Osteoarthritis is no longer common only among the elderly but has extended to the younger population who also need a long-term solution for their painful problem [10].

Currently, surgical treatments for knee osteoarthritis include arthroscopic microfracture, Osteoarticular Transfer System (OATS), and autologous chondrocyte implantation (ACI), as well as open procedures such as osteotomy and arthroplasty. Unfortunately, they all fail to provide healthy and vigorous articular cartilage in the long run. For example, osteotomy and arthroplasty can lead to articular exacerbation and impairment of neighboring bones [5]. Cartilage tissue engineering, on the other hand, may provide a potentially better resolution in the treatment of knee osteoarthritis. With scaffolds manufactured especially for articular cartilage, the functional complexity of electrospun scaffolds provides 


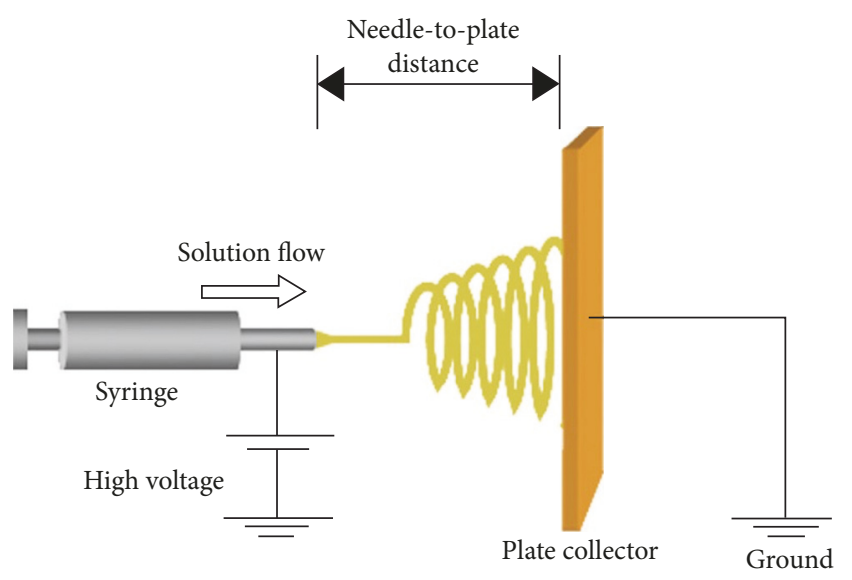

FIGURE 1: Typical electrospinning facility with a plate collector [6].

significant advantages over other techniques such as allowing the mesenchymal stem cells to grow in a way that facilitates the formation of fibrous tissue structure. Electrospinning may be a viable approach to achieving highly aligned and biocompatible scaffolds to meet the demands for cartilage tissue engineering.

1.1. Electrospinning. An electrospinning system is comprised of at least three units: a high voltage power unit, a material delivery unit (a capillary tube with a small spinneret in general), and a fiber collection unit. A typical electrospinning setup is shown in Figure 1 [6]. The randomly distributed nanofibers were collected in Figure 1 on a vertical plate. Usually, an advancement pump is employed to regulate the flow rate of polymeric solution discharged from a syringe. An electrically charged jet of polymer solution or melt is created by a high voltage source. The discharged polymer solution jet goes through an instability process, during which the jet is elongated and the solvent evaporates or solidifies. The jet is finally collected as an interconnected web of ultrathin fibers at the collector that is grounded or connected to an electrode. The diameters of electrospun fibers can range from $10 \mathrm{~nm}$ to $100 \mu \mathrm{m}$ depending on the material, device configuration, and process setup.

Electrospinning is able to generate loosely connected porous mats from submicrometer to nanometer scales in diameter as it is a highly flexible technique to produce continuous fibers. The nanofiber mat yields a high surface area to volume ratio and high porosity [54]. The nanostructure of the mat mimics the structure of the ECM in terms of both morphology and composition [55]. Various patterns of electrospun nanofibers have been fabricated for different biomedical applications ranging from artificial skin to endocrine organs and from the nervous system to cardiovascular tissues [56].

1.2. Electrospun Scaffolds for Cartilage Tissue Engineering. Electrospinning as a feasible and versatile technique can manipulate both natural and artificial polymers in nanoscale and promote the proliferation of mesenchymal stem cells (MSCs). Recent research attention has focused on improving the material design of the composition to produce biomimetic, gradient, and 3D scaffolds. Biomimetic scaffold is crucial in the reconstruction of connective tissue such as articular cartilage. Electrospinning may achieve the desired biomimetic characteristics with regard to biocompatibility and biomimicry by adding different synthetic and biological materials to the electrospinning nanofibers. Because tissue composition exhibits gradient features from the top layer that withstands high pressure to the bottom layer that connects with the subchondral bone, gradient scaffolds are needed for cartilage tissue engineering. Fibers generated during electrospinning tend to accumulate in a limited thickness and form a denser instead of thicker scaffold; therefore, strategies of fabricating thicker 3D electrospun scaffolds are crucial.

1.3. Objectives. The objective of this paper is to review and discuss the recent trends of electrospinning strategies for cartilage tissue engineering, particularly the biomimetic, gradient, and 3D scaffolds, along with future prospects of potential clinical applications in this field of research.

\section{Method of Literature Search}

Literature selection for this article was based on PubMed, Scopus, Google Scholar, ScienceDirect, and Web of Science databases from 2011 to the present, as the last review paper on this topic was published in 2012 [57]. The search was conducted using different combinations of the following terms: "tissue engineering," "electrospinning," "cartilage," "scaffold," and "bioscaffold." Articles that were considered to be related to this review and written in English were included.

\section{Literature Review}

The current literature review reveals that the most prevailing recent trend is the fabrication of biomimetic, gradient, and $3 \mathrm{D}$ bioscaffolds, as presented below.

3.1. Biomimetic Composite Scaffolds. The desired characteristics of electrospun scaffold for cartilage regeneration include biocompatibility and biomimicry. Different synthetic and biological materials may be added to electrospinning nanofibers to achieve these characteristics. Cao et al. added graphene oxide with poly(vinyl alcohol) (PVA) and chitosan for better biocompatibility and produced uniform nanofibers with improved cell growth rate compared with nanofibers of chitosan and PVA alone [23]. Bioprinting and electrospinning were combined to fabricate biomimetic scaffolds for cartilage tissue engineering [13]. Electrospun fiber assembled hydrogel was also utilized for supplementation of glycosaminoglycan enriched and mineralized cartilage [18].

3.1.1. Structure Biomimicry. Combination of natural and artificial polymers for scaffolds fabrication is considered promising for repair of cartilage defect or damage. For example, better chondrocytes adhesion and spreading efficiency were achieved with a poly(L-lactic-acid) (PLLA)/silk fibroin (SF) composite scaffold [20]. Poly(L-lactide-co-caprolactone) $(\mathrm{P}(\mathrm{LL}-\mathrm{CL}))$ and gelatin were used for porous scaffolds fabrication to improve water absorption, cell infiltration, and 
shape-forming [21]. He et al. investigated the feasibility of collagen/poly(L-lactic acid-co- $\varepsilon$-caprolactone) membranes to facilitate cartilage-like tissue formation [14]. Similarly, Sadeghi et al. blended polyhydroxybutyrate (PHB) with chitosan (CTS) to produce hydrophilic fibrous scaffold for better chondrocytes attachment [22]. The advantages of gelatin/polycaprolactone (PCL) on the formation of $3 \mathrm{D}$ cartilage regeneration have also been demonstrated $[17,58]$.

Biocompatible polymers can be electrospun with wound healing and antimicrobial agents, such as alkanin and shikonin, to achieve high drug capturing efficiencies and multifunctional activities [11]. Yin et al. fabricated core-shell structure nanofibers with embedded kartogenin solution as core fluid to facilitate cartilage regeneration [24]. Mirzaei et al. incorporated glucosamine into PLLA/PEG scaffolds to achieve an enhanced cell proliferation rate [25]. These composite structures can be used to facilitate chondrogenic differentiation and cartilage repair. Oriented electrospinning scaffold thereby exhibits superb biomimicry of articular cartilage by modifying cell adhesion and distribution.

Posttreatment can also benefit biomimetic scaffold fabrication. Liu et al. freeze-dried electrospun fibers with a tricalcium phosphate and produced a trilayered scaffold consisting of oriented fibrous network providing promoted orientation of mesenchymal stem cells [15].

3.1.2. Signal Biomimicry. Sustained and stable release of biomolecules such as growth factors, biological signals, and proteins remains an issue that needs to be resolved. Growth factors such as Nel-like molecule-1 have been preloaded in nanofibers via two-phase electrospinning to achieve prolonged release time as well as enhanced MSCs growth rate [26]. A core-sheath structure fibrous electrospun scaffold was fabricated by Man et al. Using a polyvinyl pyrrolidone/bovine serum albumin/rhTGF- $\beta 1$ composite solution as the core fluid and poly( $\varepsilon$-caprolactone) solution as the sheath fluid, the scaffolds revealed sustained rhTGF- $\beta 1$ release and promoted chondrogenic differentiation [16]. MSC chondrogenesis was also enhanced on cellulose derived glycosaminoglycan mimetic scaffolds by Huang et al., given that glycosaminoglycans provide signaling cues in native cartilage tissue [19]. Liao et al. coated cartilaginous ECM on electrospun PCL microfiber scaffolds to enhance MSC chondrogenesis [59]. Composite scaffolds such as poly(vinyl alcohol)/polycaprolactone (PVA/PCL) scaffold seeded with MSC also showed better cartilage defects healing effect [12].

Some important electrospinning-based methods to fabricate biomimetic composite scaffolds for cartilage tissue engineering are summarized in Table 1 . All of the papers cited in Table 1 are directly or possibly related to articular cartilage tissue engineering applications, such as tracheal cartilage engineering.

3.2. Gradient Scaffolds. Several methods of generating gradient scaffolds have been reported by researchers such as structure and composition gradient. He et al. first deposited a layer of aligned nanofibers of pure poly(L-lactide-co-glycolide) acid (PLGA) on a cylindrical surface and then deposited a layer of aligned nanofibers of PLGA/nanohydroxyapatite
(HA) on top. The microstructural organization and nano-HA content in electrospun scaffolds exhibit gradient change [33] and the anisotropic strain was also eliminated in scaffolds with fiber diameter gradient in Grey et al.s research [30]. Guided spatial differentiation of MSCs [28] was also observed in composition and biomolecule gradient scaffolds. The scaffolds exhibit superior material properties in burst testing. The biodegradation rate and biological functions were controlled in Angarano et al.s fiber diameter gradient scaffolds [31].

Fabricating scaffolds with gradients of molecules and element particles for tissue engineering has drawn substantial attention. Chondroitin sulfate (CS) and gentamycin sulfate (GS) gradients have been achieved with mineralized cartilage [18] and spatiotemporal drug release [35]. Ramalingam et al. reported a scaffold with amorphous calcium phosphate nanoparticles (nACP) gradient by coelectrospinning. Adhesion and proliferation of osteogenic cells were enhanced in gradient regions that have higher nACP concentration with a graded osteoblast response [29]. The graded cells' outgrowth rate and osteogenesis were also found to be positively related to the protein concentration gradient [27] and mineral gradient [34] on scaffolds, respectively.

Scaffolds with chemical and mechanical property gradient have also been investigated. Samavedi et al. demonstrated the possibility of fabricating a mechanochemical gradient scaffold with graded meshes by using controlled infusion of encapsulated $\mathrm{CaCO}_{3}$ and $\mathrm{TiO}_{2}$ nanoparticles [60]. The cell viability has shown preliminary evidence regarding the suitability of these scaffolds for in vitro tissue engineering.

Some important electrospinning-based methods to fabricate gradient scaffolds used in cartilage tissue engineering are summarized in Table 2. All of the papers cited in Table 2 are directly or possibly related to articular cartilage tissue engineering applications, such as interfacial tissue engineering and soft tissue regeneration.

3.3. $2 D$ Scaffolds versus $3 D$ Scaffolds. One of the major issues of conventional electrospun nanofibrous scaffolds is the limited thickness (typically $<1 \mathrm{~mm}$ ) [61]. While 2D scaffolds are widely used in tissue engineering applications, they still fall short of contributing to crucial factors such as cell communication in ECM context, mechanical cues, and nutrient transportation [62]. 3D scaffolds, on the other hand, have superior cell differentiation and development rate, especially for connective tissues such as articular cartilage [53], and can improve cell infiltration rate with larger pore size and higher porosity [50]. The oriented electrospun fibers in 3D scale can guide the MSCs to grow in certain direction and further promote the formation of oriented and connective tissue. Further, in fabricating 3D multiphasic scaffolds where the scaffolds are separated spatially into different sections for guided MSCs differentiation mimicking the structure of connective tissues such as articular cartilage, electrospinning as a less complicated process for producing aligned fibers in 3D scale could demonstrate advantages in fabricating multiphasic scaffolds.

Among a multitude of applications for 3D organization of the nanofibers, processing the nanofibrous mesh into a desirable form after electrospinning has attracted substantial 
TABLE 1: Summary of electrospinning-based techniques for fabrication of biomimetic composite scaffolds.

\begin{tabular}{|c|c|c|c|c|}
\hline Authors & Year & Technique & Results & Application \\
\hline $\begin{array}{l}\text { Kontogiannopoulos et al. } \\
\text { [11] }\end{array}$ & 2011 & $\begin{array}{c}\text { Incorporated wound } \\
\text { healing and antimicrobial } \\
\text { agents }\end{array}$ & $\begin{array}{l}\text { High drug entrapment } \\
\text { efficiencies and } \\
\text { multifunctional activities }\end{array}$ & $\begin{array}{l}\text { Tissue engineering } \\
\text { scaffolds }\end{array}$ \\
\hline Shafiee et al. [12] & 2011 & $\begin{array}{l}\text { Seed MSC in electrospun } \\
\text { scaffold }\end{array}$ & $\begin{array}{l}\text { Improved cartilage defects } \\
\text { healing }\end{array}$ & $\begin{array}{l}\text { Bone and cartilage tissue } \\
\text { engineering }\end{array}$ \\
\hline Xu et al. [13] & 2012 & $\begin{array}{l}\text { Bioprinting and } \\
\text { electrospinning }\end{array}$ & $\begin{array}{l}80 \% \text { survived chondrocytes } \\
\text { and cartilage-like tissue } \\
\text { formation }\end{array}$ & Cartilage tissue engineering \\
\hline He et al. [14] & 2013 & Electrospinning & $\begin{array}{c}\text { Cartilage-like tissue } \\
\text { formation }\end{array}$ & Cartilage tissue engineering \\
\hline Liu et al. [15] & 2014 & $\begin{array}{c}\text { Freeze-dried } \\
\text { electrospinning }\end{array}$ & $\begin{array}{l}\text { Successful regenerated } \\
\text { osteochondral defects }\end{array}$ & $\begin{array}{c}\text { Triphasic osteochondral } \\
\text { implant }\end{array}$ \\
\hline Man et al. [16] & 2014 & Electrospinning & $\begin{array}{c}\text { Sustained rhTGF- } \beta 1 \text { release } \\
\text { and better chondrogenic } \\
\text { differentiation }\end{array}$ & Cartilage tissue engineering \\
\hline Zheng et al. [17] & 2014 & Electrospinning & $3 \mathrm{D}$ cartilage regeneration & Cartilage tissue engineering \\
\hline Mohan et al. [18] & 2015 & $\begin{array}{c}\text { Electrospun fiber } \\
\text { assembled hydrogel }\end{array}$ & $\begin{array}{l}\text { Sustained release of } \\
\text { chondroitin sulfate }\end{array}$ & Cartilage tissue engineering \\
\hline Huang et al. [19] & 2016 & Electrospinning & $\begin{array}{l}\text { Enhanced MSC } \\
\text { chondrogenesis }\end{array}$ & Cartilage tissue engineering \\
\hline Li et al. [20] & 2016 & Composite electrospinning & $\begin{array}{l}\text { Better chondrocytes } \\
\text { adhesion and filtration }\end{array}$ & Cartilage tissue engineering \\
\hline Kalaithong et al. [21] & 2016 & $\begin{array}{l}\text { Electrospinning and wet } \\
\text { spinning } \\
\end{array}$ & $\begin{array}{l}\text { Better water absorption and } \\
\text { cell infiltration }\end{array}$ & Cartilage tissue engineering \\
\hline Sadeghi et al. [22] & 2016 & Electrospinning & $\begin{array}{c}\text { Better hydrophilic property } \\
\text { and cell attachment }\end{array}$ & Cartilage tissue engineering \\
\hline Cao et al. [23] & 2017 & $\begin{array}{c}\text { Chitosan/graphene oxide } \\
\text { polymer nanofiber }\end{array}$ & $\begin{array}{c}\text { Better biocompatibility and } \\
\text { cell growth rate }\end{array}$ & Cartilage tissue engineering \\
\hline Yin et al. [24] & 2017 & $\begin{array}{c}\text { Core-shell structure } \\
\text { nanofiber with embedded } \\
\text { kartogenin solution }\end{array}$ & $\begin{array}{l}\text { Promoted chondrogenic } \\
\text { differentiation }\end{array}$ & $\begin{array}{l}\text { Tracheal cartilage } \\
\text { regeneration }\end{array}$ \\
\hline Mirzaei et al. [25] & 2017 & $\begin{array}{l}\text { Glucosamine incorporated } \\
\text { into PLLA/PEG scaffolds }\end{array}$ & $\begin{array}{c}\text { Enhanced cell proliferation } \\
\text { rate }\end{array}$ & Cartilage tissue engineering \\
\hline Wang et al. [26] & 2017 & Two-phase electrospinning & $\begin{array}{c}\text { Prolonged drug release } \\
\text { time and enhanced MSCs } \\
\text { growth rate }\end{array}$ & Cartilage tissue engineering \\
\hline
\end{tabular}

interest. For example, a 3D scaffold can be created by stacking multiple layers of nanofiber mesh for cell seeding [48]. Garrigues et al. found that multilayer scaffolds enhanced cell infiltration aggrecan (ACAN) gene expression [46]. Yunos et al. designed a bilayered scaffold by combining electrospun fibers with bioglass and obtained viable chondrocyte cells in the scaffold [43]. Xue et al. prepared the electrospun gelatin/PCL membranes into rounded shape with seeded chondrocytes to culture an ear-shaped cartilage, with good elasticity and impressive mechanical strength [45]. Kai et al. incorporated electrospun fibers into hydrogel to improve mechanical properties such as compressive strength [39]. The advantage of this simple method is the high degree of flexibility in creating the ultimate geometry of scaffolds.

Modified electrospinning setups can also be utilized for $3 \mathrm{D}$ structure such as electrospinning with external heat source [38] and dual nozzle extrusion system to improve cell infiltration rate. He et al. increased the pore size of scaffolds by near-field electrospinning [63]. Levorson et al. also increased cellular infiltration with multiscale scaffold, which contains microfibers and nanofibers evenly distributed throughout the entire construct [44]. Human mesenchymal cells were found to maintain scaffold cellularity under serum-free conditions with these scaffolds. A fluffy 3D scaffold with randomly and evenly oriented fibers in all directions was also fabricated by utilizing the electrostatic repulsion between fibers; the cell proliferation rate observed was 5 times as fast as the $2 \mathrm{D}$ scaffold counterparts after one week [42].

Novel electrospinning solutions have also been investigated for 3D electrospinning. For example, $\mathrm{Xu}$ et al. started from a polymer solution with de-cross-linked keratin from chicken feathers to obtain intrinsic water stability for $3 \mathrm{D}$ scaffold [47]. Enhancement of cartilage repairing can also be achieved by scaffolds with cross-linked hyaluronic acid [51] 
TABLE 2: Summary of electrospinning-based techniques for fabricating gradient scaffolds.

\begin{tabular}{|c|c|c|c|c|c|}
\hline Authors & Year & $\begin{array}{c}\text { Gradient } \\
\text { parameter(s) }\end{array}$ & Technique & Results & Application \\
\hline Zander et al. [27] & 2012 & $\begin{array}{c}\text { Protein concentration } \\
\text { gradient }\end{array}$ & $\begin{array}{l}\text { Air-plasma-modified } \\
\text { electrospinning }\end{array}$ & $\begin{array}{l}\text { Corresponding cell } \\
\text { outgrowth rate }\end{array}$ & Tissue engineering \\
\hline Zhang et al. [28] & 2012 & $\begin{array}{c}\text { Composition and } \\
\text { biomolecule gradient }\end{array}$ & $\begin{array}{l}\text { Microfluidic assisted } \\
\text { electrospinning }\end{array}$ & $\begin{array}{c}\text { Guided spatial cell } \\
\text { differentiation }\end{array}$ & Tissue engineering \\
\hline Ramalingam et al. [29] & 2013 & Composition gradient & Coelectrospinning & $\begin{array}{c}\text { Enhanced osteogenic } \\
\text { cells proliferation and } \\
\text { adhesion }\end{array}$ & $\begin{array}{l}\text { Interfacial tissue } \\
\text { engineering }\end{array}$ \\
\hline Grey et al. [30] & 2013 & $\begin{array}{l}\text { Fiber diameter } \\
\text { gradient }\end{array}$ & $\begin{array}{c}\text { Gradient } \\
\text { electrospinning }\end{array}$ & $\begin{array}{l}\text { Enhanced mechanical } \\
\text { properties }\end{array}$ & Tissue engineering \\
\hline Angarano et al. [31] & 2013 & $\begin{array}{c}\text { Fiber diameter } \\
\text { gradient }\end{array}$ & $\begin{array}{c}\text { Reactive } \\
\text { electrospinning } \\
\end{array}$ & $\begin{array}{c}\text { Gradient } \\
\text { biodegradation rate }\end{array}$ & $\begin{array}{c}\text { Soft tissue } \\
\text { regeneration }\end{array}$ \\
\hline Sundararaghavan et al. [32] & 2013 & $\begin{array}{l}\text { Growth factor } \\
\text { gradient }\end{array}$ & $\begin{array}{c}\text { Gradient } \\
\text { electrospinning } \\
\end{array}$ & $\begin{array}{l}\text { Directed cell motility } \\
\text { in gradient direction }\end{array}$ & Tissue engineering \\
\hline He et al. [33] & 2014 & $\begin{array}{c}\text { Structure and } \\
\text { composition gradient }\end{array}$ & $\begin{array}{c}\text { Modified } \\
\text { coelectrospinning }\end{array}$ & $\begin{array}{c}\text { Gradient cell } \\
\text { metabolic activity }\end{array}$ & Tissue engineering \\
\hline Liu et al. [34] & 2014 & Mineral gradient & $\begin{array}{l}\text { Graded mineral } \\
\text { coating }\end{array}$ & $\begin{array}{c}\text { Graded mesenchymal } \\
\text { stem cells } \\
\text { osteogenesis } \\
\end{array}$ & $\begin{array}{l}\text { Interfacial tissue } \\
\text { engineering }\end{array}$ \\
\hline Mohan et al. [18] & 2015 & CS and BG gradient & $\begin{array}{l}\text { Electrospun fiber } \\
\text { assembled hydrogel }\end{array}$ & $\begin{array}{l}\text { Glycosaminoglycan } \\
\text { enriched and } \\
\text { mineralized cartilage } \\
\text { formation }\end{array}$ & $\begin{array}{l}\text { Cartilage tissue } \\
\text { engineering }\end{array}$ \\
\hline Liu et al. [35] & 2016 & GS and deferoxamine & $\begin{array}{l}\text { 3D bioprinting and } \\
\text { electrospinning }\end{array}$ & $\begin{array}{c}\text { Spatiotemporal drug } \\
\text { release }\end{array}$ & $\begin{array}{l}\text { Osteochondral tissue } \\
\text { engineering }\end{array}$ \\
\hline
\end{tabular}

and biological cue chondroitin sulfate-incorporated electrospinning [37]. Wei et al. combined poly[(butylene succinate)co-adipate] (PBSA) and PLLA to culture primary human chondrocytes (PHCs) in electrospun 3D fibrous scaffolds for improved cell attachment and proliferation [40].

Another strategy for fabricating 3D scaffold is combining electrospinning with other advanced manufacturing techniques such as $3 \mathrm{D}$ printing and freeze-drying. In the research by $\mathrm{Xu}$ et al. about hybrid inkjet printing and electrospinning system, the cell viability was $80 \%$ after one week, and cartilage-like tissue has formed both in vitro and in vivo [13]. Afonso et al. combined another advanced manufacturing technique, direct writing, with electrospinning to obtain oriented fibers and a highly controlled scaffold structure [52]. Liu et al. enhanced the mechanical strength of electrospinning by freeze-drying, and osteochondral defects were repaired in a rabbit model [49].

Last but not least, 3D structure can be achieved with different postprocess treatments. Holmes et al. improved mechanical properties of the 3D scaffolds with hydrogen treated multiwalled carbon nanotubes (MWCNTs) [41]. Zhu et al's scaffolds enhanced chondrogenic differentiation and cell infiltration rate with cold atmospheric plasma treated electrospinning [50]. Chen and Su also demonstrated better viability, proliferation, and differentiation of rabbit articular chondrocytes, with plasma-treatment electrospun scaffold [36].

Some important electrospinning-based methods to construct 3D nanostructures for the scaffolds used in tissue engineering are summarized in Table 3. All of the papers cited in Table 3 are directly or possibly related to articular cartilage tissue engineering applications, such as osteochondral tissue replacement and MSC chondrogenesis.

\section{Discussion}

Electrospinning provides an efficient way of fabricating cartilage tissue engineering scaffolds with nanoscale elements and utilization of a wide range of polymers. The process can be easily modified for various biomedical applications. Although there have been progress and improvements in recent years, very limited research has been reported on complete articular cartilage repair or major improvement in tissue engineering for comprehensive treatment of related diseases such as arthritis. There is hardly any parameter optimization for refined fiber strength and geometry. The complexity of electrospinning setups is growing rapidly as it incorporates more and more novel techniques such as biological cue-incorporated electrospinning [37], hydrogel [39], hybrid 3D printing [13], and cold atmospheric plasma treatment [50]. On one hand, it is highly challenging to deal with greater magnitude of parameters and characteristic architectures. On the other hand, these 3D scaffold strategies incorporating different techniques all come with certain weaknesses or vulnerabilities such as small thickness and microscale (instead of nanoscale) fibers (>200 nm). Therefore, the possibility of clinical application of these techniques on a large scale is still fairly slim. 


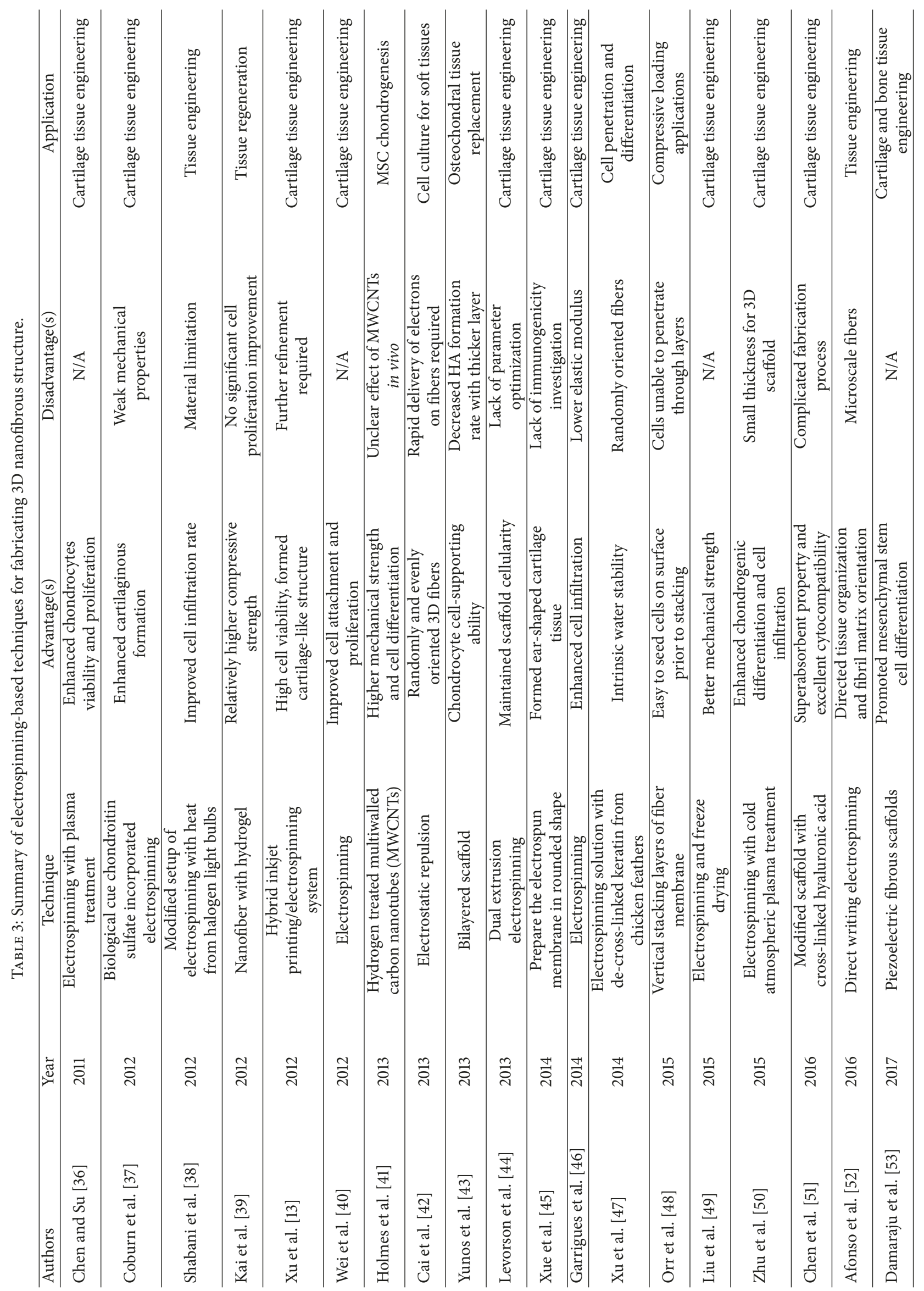


Several electrospinning strategies have been developed for fabricating biomimetic composite scaffolds. Along with antimicrobial agents and growth factors, both structure and signal biomimetic scaffolds produced exhibit suitable biocompatibility and intermediate level of biomimicry. However, the effects of fiber-guided cell orientation on chondrogenic differentiation, attachment, and mineralization of marrow mesenchymal stem cells need to be further investigated and so should optimization for cell culture and electrospinning process.

Various improvements in mechanical properties of scaffolds, such as microstructural organization [33], tensile strength [60,64], and anisotropic strain [30], have been achieved with different gradient properties. However, all of the improved mechanical properties, such as tensile strength, are still in the undesired low range $(<10 \mathrm{MPa})$ [13]. And there are no quantitative results for the effect of enhanced mechanical properties on cell proliferation rate. In some cases, the overall mechanical strength was found to be even lower than that of the control scaffolds with no gradient. To address this issue, $3 \mathrm{D}$ electrospun fibers were immersed into a medium, such as hydrogel, to improve their mechanical strengths [39]; however, the electrospun fibers dissolve much faster than hydrogel in cell culture. Also, hardly any research has addressed the issue of mechanical properties of $3 \mathrm{D}$ scaffolds. These issues need to have experimental justification to verify that the improvement of these mechanical properties is helpful for in vitro and in vivo cell proliferation.

Using different gradient scaffolds, researchers were able to create graded cell response [29], outgrowth rate [27], and biodegradation rate [31] in a single scaffold. In vivo studies are needed to investigate the effects and suitability of these gradient scaffolds employed in cartilage implants, as well as related interfacial tissue engineering.

Although electrospun scaffolds possess higher porosity than other forms of scaffolds, a common drawback is the limited size of pores, which further prevents cells from growing in the scaffold [65]. Several measures have been investigated to address this issue, such as using sacrificial fibers [66], multiscale scaffold [44], hybrid scaffold [67], near-field electrospinning [63], and salt leaching and ice crystals [20]. These techniques could also be incorporated in 3D scaffolds fabrication for better cell infiltration.

The positive effects of $3 \mathrm{D}$ scaffolds on cell infiltration rate $[44,63]$ and cell proliferation rate [42] have been extensively investigated and verified. Other crucial properties in cell culture such as water stability [47] and cartilage-like tissue formation $[37,51]$ have also been investigated, demonstrating the intrinsic advantages of 3D scaffolds over 2D scaffolds. The biodegradation rate and biomimicry level should be further characterized quantitatively before $3 \mathrm{D}$ scaffolds can be implemented as cartilage implants in vivo.

Electrospun scaffolds for cartilage tissue engineering still face major challenges in biomechanical and biological properties. More novel synthetic and artificial materials need to be explored and tested with regard to issues such as mechanical strength, biotoxicity, biocompatibility, and biodegradability before research focus can switch to large-scale applications. Fabrication procedures need to be modified and improved in terms of facility and process parameters for better biomimicry and cost effectiveness. After further optimization of biomimetic, gradient, and 3D electrospun scaffolds along with the incorporation of advanced manufacturing techniques and novel materials, electrospun scaffolds exhibit substantial potential for cartilage tissue engineering.

\section{Conclusion}

This paper presents a variety of electrospinning strategies with novel materials and manufacturing techniques of bioscaffolds for cartilage tissue engineering. The literature review reveals that the most prevailing recent trend is the fabrication of biomimetic, gradient, and 3D bioscaffolds. Natural polymeric and biological materials have been incorporated into electrospinning technique with synthetic materials to improve biomimicry and biocompatibility. Multiple approaches have been taken in electrospinning to form 3D scaffolds with cartilage-like structure and enhanced chondrogenic differentiation. Mechanical properties of scaffolds have been improved by various electrospinning strategies to achieve acceptable levels. Future research should focus on issues such as mechanical strength, biotoxicity, and biodegradability in vivo to pave the way for possible human trials.

\section{Conflicts of Interest}

The authors declare that there are no conflicts of interest.

\section{References}

[1] J. M. Holzwarth and P. X. Ma, "Biomimetic nanofibrous scaffolds for bone tissue engineering," Biomaterials, vol. 32, no. 36, pp. 9622-9629, 2011.

[2] B. P. Chan and K. W. Leong, "Scaffolding in tissue engineering: general approaches and tissue-specific considerations," European Spine Journal, vol. 17, no. 4, pp. S467-S479, 2008.

[3] F. J. O’Brein, "Biomaterials \& scaffolds for tissue engineering," Materials Today, vol. 14, no. 3, pp. 88-95, 2011.

[4] E. Carletti, A. Motta, and C. Migliaresi, "Scaffolds for tissue engineering and 3D cell culture.," Methods in Molecular Biology (Clifton, N.J.), vol. 695, pp. 17-39, 2011.

[5] Z. Izadifar, X. Chen, and W. Kulyk, "Strategic design and fabrication of engineered scaffolds for articular cartilage repair," Journal of Functional Biomaterials, vol. 3, no. 4, pp. 799-838, 2012.

[6] Q. P. Pham, U. Sharma, and A. G. Mikos, "Electrospinning of polymeric nanofibers for tissue engineering applications: a review," Tissue Engineering Part A, vol. 12, no. 5, pp. 1197-1211, 2006.

[7] N. Hamann, F. Zaucke, J. Heilig, K. D. Oberländer, G.-P. Brüggemann, and A. Niehoff, "Effect of different running modes on the morphological, biochemical, and mechanical properties of articular cartilage," Scandinavian Journal of Medicine \& Science in Sports, vol. 24, no. 1, pp. 179-188, 2014.

[8] A. M. Haleem and C. R. Chu, "Advances in tissue engineering techniques for articular cartilage repair," Operative Techniques in Orthopaedics, vol. 20, no. 2, pp. 76-89, 2010. 
[9] A. Collins, J. T. Blackburn, C. Olcott, B. Yu, and P. Weinhold, "The impact of stochastic resonance electrical stimulation and knee sleeve on impulsive loading and muscle co-contraction during gait in knee osteoarthritis," Clinical Biomechanics, vol. 26, no. 8, pp. 853-858, 2011.

[10] K. Huétink, B. C. Stoel, I. Watt et al., "Identification of factors associated with the development of knee osteoarthritis in a young to middle-aged cohort of patients with knee complaints," Clinical Rheumatology, vol. 34, no. 10, pp. 1769-1779, 2015.

[11] K. N. Kontogiannopoulos, A. N. Assimopoulou, I. Tsivintzelis, C. Panayiotou, and V. P. Papageorgiou, "Electrospun fiber mats containing shikonin and derivatives with potential biomedical applications," International Journal of Pharmaceutics, vol. 409, no. 1-2, pp. 216-228, 2011.

[12] A. Shafiee, M. Soleimani, G. A. Chamheidari et al., "Electrospun nanofiber-based regeneration of cartilage enhanced by mesenchymal stem cells," Journal of Biomedical Materials Research Part A, vol. 99, no. 3, pp. 467-478, 2011.

[13] T. Xu, K. W. Binder, M. Z. Albanna et al., "Hybrid printing of mechanically and biologically improved constructs for cartilage tissue engineering applications," Biofabrication, vol. 5, no. 1 , Article ID 015001, 2013.

[14] X. He, W. Fu, B. Feng et al., "Electrospun collagen-poly(Llactic acid-co- $\varepsilon$-caprolactone) membranes for cartilage tissue engineering," Journal of Regenerative Medicine, vol. 8, no. 4, pp. 425-436, 2013.

[15] X. Liu, S. Liu, S. Liu, and W. Cui, "Evaluation of oriented electrospun fibers for periosteal flap regeneration in biomimetic triphasic osteochondral implant," Journal of Biomedical Materials Research Part B: Applied Biomaterials, vol. 102, no. 7, pp. 1407-1414, 2014.

[16] Z. Man, L. Yin, Z. Shao et al., "The effects of co-delivery of BMSC-affinity peptide and rhTGF- $\beta 1$ from coaxial electrospun scaffolds on chondrogenic differentiation," Biomaterials, vol. 35, no. 19, pp. 5250-5260, 2014.

[17] R. Zheng, H. Duan, J. Xue et al., "The influence of Gelatin/PCL ratio and 3-D construct shape of electrospun membranes on cartilage regeneration," Biomaterials, vol. 35, no. 1, pp. 152-164, 2014.

[18] N. Mohan, J. Wilson, D. Joseph, D. Vaikkath, and P. D. Nair, "Biomimetic fiber assembled gradient hydrogel to engineer glycosaminoglycan enriched and mineralized cartilage: An in vitro study," Journal of Biomedical Materials Research Part A, vol. 103, no. 12, pp. 3896-3906, 2015.

[19] G. P. Huang, A. Molina, N. Tran, G. Collins, and T. L. Arinzeh, "Investigating cellulose derived glycosaminoglycan mimetic scaffolds for cartilage tissue engineering applications," Journal of Tissue Engineering and Regenerative Medicine, 2017.

[20] Z. Li, P. Liu, T. Yang et al., "Composite poly(l-lactic-acid)/silk fibroin scaffold prepared by electrospinning promotes chondrogenesis for cartilage tissue engineering," Journal of Biomaterials Applications, vol. 30, no. 10, pp. 1552-1565, 2015.

[21] W. Kalaithong, R. Molloy, T. Theerathanagorn, and W. Janvikul, "Novel poly(l-lactide-co-caprolactone)/gelatin porous scaffolds for use in articular cartilage tissue engineering: Comparison of electrospinning and wet spinning processing methods," Polymer Engineering \& Science, 2016.

[22] D. Sadeghi, S. Karbasi, S. Razavi, S. Mohammadi, M. A. Shokrgozar, and S. Bonakdar, "Electrospun poly(hydroxybutyrate)/ chitosan blend fibrous scaffolds for cartilage tissue engineering,"
Journal of Applied Polymer Science, vol. 133, no. 47, Article ID 44171, 2016.

[23] L. Cao, F. Zhang, Q. Wang, and X. Wu, "Fabrication of chitosan/graphene oxide polymer nanofiber and its biocompatibility for cartilage tissue engineering," Materials Science and Engineering C: Materials for Biological Applications, vol. 79, pp. 697-701, 2017.

[24] H. Yin, J. Wang, Z. Gu et al., "Evaluation of the potential of kartogenin encapsulated poly(L-lactic acid-co-caprolactone)/ collagen nanofibers for tracheal cartilage regeneration," Journal of Biomaterials Applications, vol. 32, no. 3, pp. 331-341, 2017.

[25] S. Mirzaei, A. Karkhaneh, M. Soleimani, A. Ardeshirylajimi, H. Seyyed Zonouzi, and H. Hanaee-Ahvaz, "Enhanced chondrogenic differentiation of stem cells using an optimized electrospun nanofibrous PLLA/PEG scaffolds loaded with glucosamine," Journal of Biomedical Materials Research Part A, vol. 105, no. 9, pp. 2461-2474, 2017.

[26] C. Wang, W. Hou, X. Guo et al., “Two-phase electrospinning to incorporate growth factors loaded chitosan nanoparticles into electrospun fibrous scaffolds for bioactivity retention and cartilage regeneration," Materials Science and Engineering C: Materials for Biological Applications, vol. 79, pp. 507-515, 2017.

[27] N. E. Zander, J. A. Orlicki, A. M. Rawlett, and T. P. Beebe, "Quantification of protein incorporated into electrospun polycaprolactone tissue engineering scaffolds," ACS Applied Materials \& Interfaces, vol. 4, no. 4, pp. 2074-2081, 2012.

[28] X. Zhang, X. Gao, L. Jiang, and J. Qin, "Flexible generation of gradient electrospinning nanofibers using a microfluidic assisted approach," Langmuir, vol. 28, no. 26, pp. 10026-10032, 2012.

[29] M. Ramalingam, M. F. Young, V. Thomas et al., "Nanofiber scaffold gradients for interfacial tissue engineering," Journal of Biomaterials Applications, vol. 27, no. 6, pp. 695-705, 2013.

[30] C. P. Grey, S. T. Newton, G. L. Bowlin, T. W. Haas, and D. G. Simpson, "Gradient fiber electrospinning of layered scaffolds using controlled transitions in fiber diameter," Biomaterials, vol. 34, no. 21, pp. 4993-5006, 2013.

[31] M. Angarano, S. Schulz, M. Fabritius et al., "Layered gradient nonwovens of in situ crosslinked electrospun collagenous nanofibers used as modular scaffold systems for soft tissue regeneration," Advanced Functional Materials, vol. 23, no. 26, pp. 3277-3285, 2013.

[32] H. G. Sundararaghavan, R. L. Saunders, D. A. Hammer, and J. A. Burdick, "Fiber alignment directs cell motility over chemotactic gradients," Biotechnology and Bioengineering, vol. 110, no. 4, pp. 1249-1254, 2013.

[33] J. He, T. Qin, Y. Liu, X. Li, D. Li, and Z. Jin, "Electrospinning of nanofibrous scaffolds with continuous structure and material gradients," Materials Letters, vol. 137, pp. 393-397, 2014.

[34] W. Liu, J. Lipner, J. Xie, C. N. Manning, S. Thomopoulos, and Y. Xia, "Nanofiber scaffolds with gradients in mineral content for spatial control of osteogenesis," ACS Applied Materials \& Interfaces, vol. 6, no. 4, pp. 2842-2849, 2014.

[35] Y.-Y. Liu, H.-C. Yu, Y. Liu, G. Liang, T. Zhang, and Q.-X. Hu, "Dual drug spatiotemporal release from functional gradient scaffolds prepared using 3D bioprinting and electrospinning," Polymer Engineering \& Science, vol. 56, no. 2, pp. 170-177, 2016.

[36] J.-P. Chen and C.-H. Su, "Surface modification of electrospun PLLA nanofibers by plasma treatment and cationized gelatin immobilization for cartilage tissue engineering," Acta Biomaterialia, vol. 7, no. 1, pp. 234-243, 2011. 
[37] J. M. Coburn, M. Gibson, S. Monagle, Z. Patterson, and J. H. Elisseeff, "Bioinspired nanofibers support chondrogenesis for articular cartilage repair," Proceedings of the National Acadamy of Sciences of the United States of America, vol. 109, no. 25, pp. 10012-10017, 2012.

[38] I. Shabani, V. Haddadi-Asl, E. Seyedjafari, and M. Soleimani, "Cellular infiltration on nanofibrous scaffolds using a modified electrospinning technique," Biochemical and Biophysical Research Communications, vol. 423, no. 1, pp. 50-54, 2012.

[39] D. Kai, M. P. Prabhakaran, B. Stahl, M. Eblenkamp, E. Wintermantel, and S. Ramakrishna, "Mechanical properties and in vitro behavior of nanofiber-hydrogel composites for tissue engineering applications," Nanotechnology, vol. 23, no. 9, Article ID 095705, 2012.

[40] J.-D. Wei, H. Tseng, E. T.-H. Chen et al., "Characterizations of chondrocyte attachment and proliferation on electrospun biodegradable scaffolds of PLLA and PBSA for use in cartilage tissue engineering," Journal of Biomaterials Applications, vol. 26, no. 8, pp. 963-985, 2012.

[41] B. Holmes, N. J. Castro, J. Li, M. Keidar, and L. G. Zhang, "Enhanced human bone marrow mesenchymal stem cell functions in novel 3D cartilage scaffolds with hydrogen treated multi-walled carbon nanotubes," Nanotechnology, vol. 24, no. 36, Article ID 365102, 2013.

[42] S. Cai, H. Xu, Q. Jiang, and Y. Yang, "Novel 3D electrospun scaffolds with fibers oriented randomly and evenly in three dimensions to closely mimic the unique architectures of extracellular matrices in soft tissues: Fabrication and mechanism study," Langmuir, vol. 29, no. 7, pp. 2311-2318, 2013.

[43] D. M. Yunos, Z. Ahmad, V. Salih, and A. R. Boccaccini, "Stratified scaffolds for osteochondral tissue engineering applications: Electrospun PDLLA nanofibre coated Bioglass ${ }^{\circledR}$-derived foams," Journal of Biomaterials Applications, vol. 27, no. 5, pp. 537-551, 2013.

[44] E. J. Levorson, P. R. Sreerekha, K. P. Chennazhi, F. K. Kasper, S. V. Nair, and A. G. Mikos, "Fabrication and characterization of multiscale electrospun scaffolds for cartilage regeneration," Biomedical Materials, vol. 8, no. 1, Article ID 014103, 2013.

[45] J. Xue, B. Feng, R. Zheng et al., "Engineering ear-shaped cartilage using electrospun fibrous membranes of gelatin/polycaprolactone," Biomaterials, vol. 34, no. 11, pp. 2624-2631, 2013.

[46] N. W. Garrigues, D. Little, J. Sanchez-Adams, D. S. Ruch, and F. Guilak, "Electrospun cartilage-derived matrix scaffolds for cartilage tissue engineering," Journal of Biomedical Materials Research Part A, vol. 102, no. 11, pp. 3998-4008, 2014.

[47] H. Xu, S. Cai, L. Xu, and Y. Yang, "Water-stable three-dimensional ultrafine fibrous scaffolds from keratin for cartilage tissue engineering," Langmuir, vol. 30, no. 28, pp. 8461-8470, 2014.

[48] S. B. Orr, A. Chainani, K. J. Hippensteel et al., "Aligned multilayered electrospun scaffolds for rotator cuff tendon tissue engineering," Acta Biomaterialia, vol. 24, article no. 3738, pp. 117-126, 2015.

[49] S. Liu, J. Wu, X. Liu et al., "Osteochondral regeneration using an oriented nanofiber yarn-collagen type I/hyaluronate hybrid/TCP biphasic scaffold," Journal of Biomedical Materials Research Part A, vol. 103, no. 2, pp. 581-592, 2015.

[50] W. Zhu, N. J. Castro, X. Cheng, M. Keidar, and L. G. Zhang, "Cold atmospheric plasma modified electrospun scaffolds with embedded microspheres for improved cartilage regeneration," PLoS ONE, vol. 10, no. 7, Article ID e0134729, 2015.
[51] W. Chen, S. Chen, Y. Morsi et al., "Superabsorbent 3D Scaffold Based on Electrospun Nanofibers for Cartilage Tissue Engineering," ACS Applied Materials \& Interfaces, vol. 8, no. 37, pp. 24415-24425, 2016.

[52] M. Afonso, C. Honglin, W. Paul, M. Carlos, T. Roman, and M. Lorenzo, "Direct writing electrospinning of scaffolds with multi-dimensional fiber architecture for hierarchical tissue engineering," Frontiers in Bioengineering and Biotechnology, vol. 4, 2016.

[53] S. M. Damaraju, Y. Shen, E. Elele et al., "Three-dimensional piezoelectric fibrous scaffolds selectively promote mesenchymal stem cell differentiation," Biomaterials, vol. 149, pp. 51-62, 2017.

[54] W. Cui, Y. Zhou, and J. Chang, "Electrospun nanofibrous materials for tissue engineering and drug delivery," Science and Technology of Advanced Materials, vol. 11, no. 1, Article ID 014108, 2010.

[55] N. G. Rim, C. S. Shin, and H. Shin, "Current approaches to electrospun nanofibers for tissue engineering," Biomedical Materials, vol. 8, no. 1, Article ID 014102, 2013.

[56] T. Jiang, E. J. Carbone, K. W.-H. Lo, and C. T. Laurencin, "Electrospinning of polymer nanofibers for tissue regeneration," Progress in Polymer Science, vol. 46, pp. 1-24, 2014.

[57] B. Holmes, N. J. Castro, L. G. Zhang, and E. Zussman, "Electrospun fibrous scaffolds for bone and cartilage tissue generation: Recent progress and future developments," Tissue Engineering Part B: Reviews, vol. 18, no. 6, pp. 478-486, 2012.

[58] X. He, B. Feng, C. Huang et al., "Electrospun gelatin/polycaprolactone nanofibrous membranes combined with a coculture of bone marrow stromal cells and chondrocytes for cartilage engineering," International Journal of Nanomedicine, vol. 10, pp. 2089-2099, 2015.

[59] J. Liao, X. Guo, K. J. Grande-Allen, F. K. Kasper, and A. G. Mikos, "Bioactive polymer/extracellular matrix scaffolds fabricated with a flow perfusion bioreactor for cartilage tissue engineering," Biomaterials, vol. 31, no. 34, pp. 8911-8920, 2010.

[60] S. Samavedi, C. Olsen Horton, S. A. Guelcher, A. S. Goldstein, and A. R. Whittington, "Fabrication of a model continuously graded co-electrospun mesh for regeneration of the ligamentbone interface," Acta Biomaterialia, vol. 7, no. 12, pp. 4131-4138, 2011.

[61] M. B. Fisher, E. A. Henning, N. Söegaard, J. L. Esterhai, and R. L. Mauck, "Organized nanofibrous scaffolds that mimic the macroscopic and microscopic architecture of the knee meniscus," Acta Biomaterialia, vol. 9, no. 1, pp. 4496-4504, 2013.

[62] T. E. Rinker and J. S. Temenoff, "Micro- and nanotechnology engineering strategies for tissue interface regeneration and repair," Tissue and Organ Regeneration: Advances in Micro- and Nanotechnology, pp. 105-155, 2014.

[63] F. He, D. Li, J. He et al., "A novel layer-structured scaffold with large pore sizes suitable for 3D cell culture prepared by near-field electrospinning," Materials Science and Engineering C: Materials for Biological Applications, vol. 86, pp. 18-27, 2018.

[64] M. Singh, N. Dormer, J. R. Salash et al., "Three-dimensional macroscopic scaffolds with a gradient in stiffness for functional regeneration of interfacial tissues," Journal of Biomedical Materials Research Part A, vol. 94, no. 3, pp. 870-876, 2010.

[65] M. M. Nava, L. Draghi, C. Giordano, and R. Pietrabissa, "The effect of scaffold pore size in cartilage tissue engineering," Journal of Applied Biomaterials and Functional Materials, vol. 14, no. 3, pp. e223-e229, 2016. 
[66] B. M. Baker, R. P. Shah, A. M. Silverstein, J. L. Esterhai, J. A. Burdick, and R. L. Mauck, "Sacrificial nanofibrous composites provide instruction without impediment and enable functional tissue formation," Proceedings of the National Acadamy of Sciences of the United States of America, vol. 109, no. 35, pp. 14176-14181, 2012.

[67] S. Karbasi, F. Fekrat, D. Semnani, S. Razavi, and E. Zargar, "Evaluation of structural and mechanical properties of electrospun nano-micro hybrid of poly hydroxybutyrate-chitosan/silk scaffold for cartilage tissue engineering," Advanced Biomedical Research, vol. 5, no. 1, p. 180, 2016. 


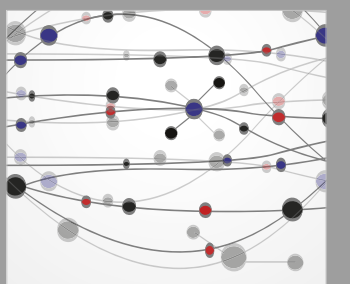

The Scientific World Journal
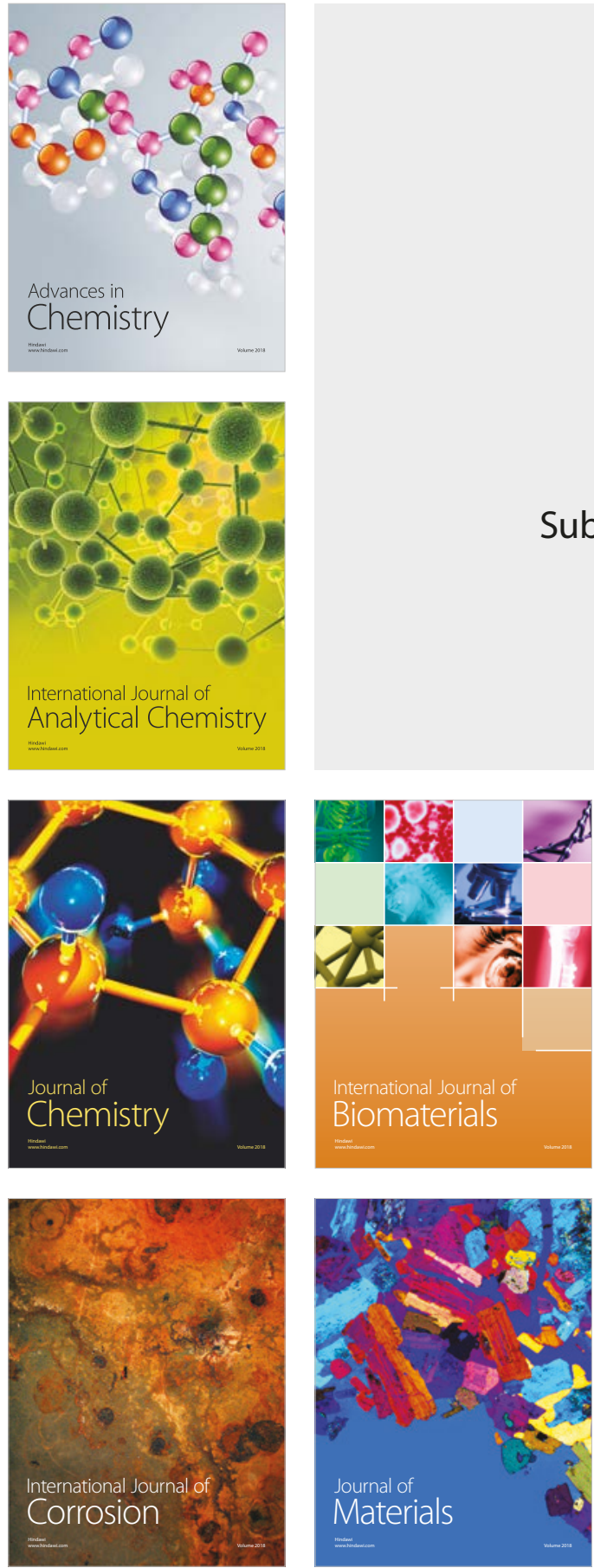

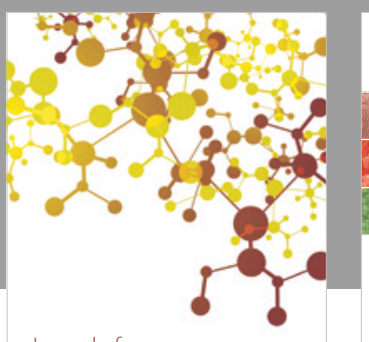

Journal of

Applied Chemistry
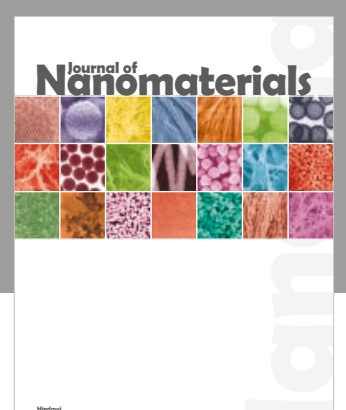

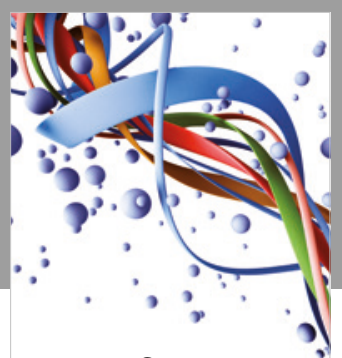

Scientifica

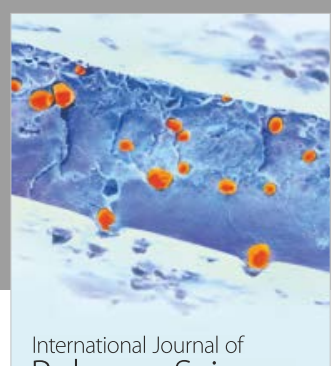

Polymer Science

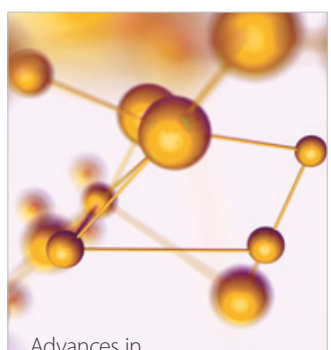

Physical Chemistry
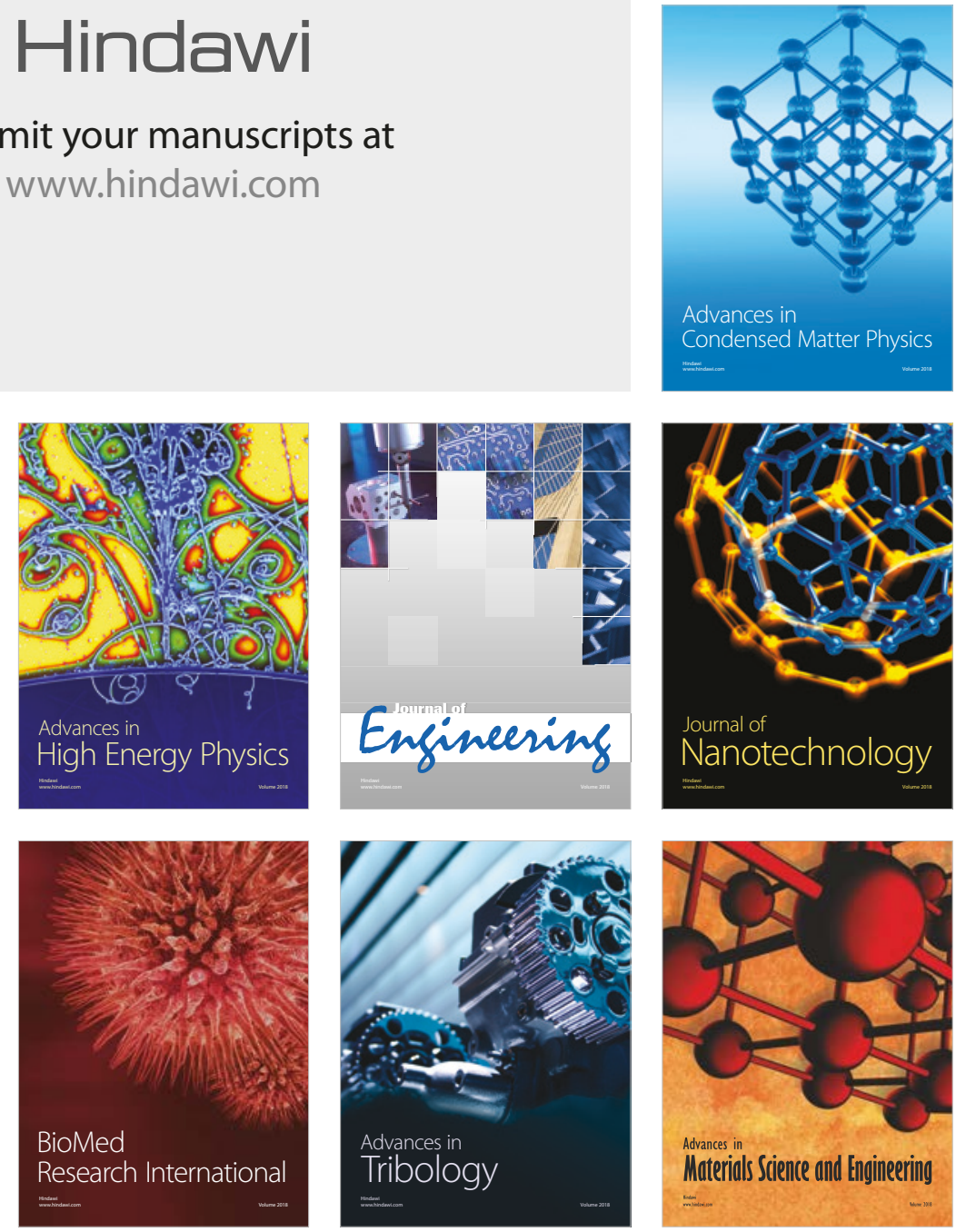